\title{
The Course Reform and Internet Teaching of New Inorganic Materials
}

\author{
Xiaohong Shi*, Kezhi Li \\ College of Materials Science and Technology, Northwestern Polytechnical University, Xi'an 710072, Shaanxi Province, \\ China \\ *Corresponding author: Xiaohong Shi, npusxh@nwpu.edu.cn

\begin{abstract}
With the continuous demand of material performance, the development of materials is rapid, and the professional curriculum teaching of "new inorganic materials" as well as its teaching methods related to the internet mandate a reform, in order to meet the needs of innovative high-quality personnel training. The update and optimization of the teaching content and methods assisted by the internet meet the needs of modern teaching and research work. More than $90 \%$ of students believe that internet teaching is conducive to the understanding of classroom knowledge and the development of innovative projects.
\end{abstract}

Keywords: New inorganic materials; Teaching reform; Internet teaching; Teaching methods

Publication date: November 2021; Online publication: November 30, 2021

\section{Introduction}

With the development of modern science and technology, high-performance and multi-function new materials play an important role in various fields, such as information, aerospace, new energy, and life sciences ${ }^{[1-4]}$. People have expected that the 21 st century would be the "second stone era," in which the demand for inorganic materials would rank the top of all kinds of materials. The category of new inorganic materials has far exceeded the conventional inorganic materials (glass, ceramics, cement, and refractory materials). The morphologies of inorganic materials have been developing from block shape to lowdimensional, thin film, single crystallization, and composite structures. The synthesis and manufacturing methods of new inorganic materials often utilize extreme conditions or technologies, such as ultra-high pressure, ultra-high temperature, super vacuum, ultra-low temperature, ultra-high-speed cooling, and ultrahigh purity. The performance of inorganic materials tends to be functional, ultimate, fine, and environment friendly; the structure and properties can also be tailored ${ }^{[5]}$. The creation of many new inorganic materials is the result of the integration of solid physics, solid chemistry, metallurgy, ceramic, biology, and information science.

The content of textbooks about new inorganic materials usually includes zero-dimensional materials, one-dimensional materials, two-dimensional materials, advanced structural ceramics, functional composites, biomaterials, and new preparation methods. In addition to the expansion of the scope of new inorganic materials, the research about these materials is constantly being strengthened. New inorganic materials are important materials to support the development of a country's economy. College students and graduate students are the builders of the new era in high-tech fields. They need to master the latest theoretical and technical achievements of relevant professional knowledge and the knowledge for future work, in order to meet the needs of social and economic development.

The teaching content, teaching methods related to the internet, and the assessment methods of the "new inorganic materials" course are discussed in this article. The aim of the course teaching is to guide students 
to understand the frontier of current inorganic materials, broaden students' knowledge, and improve their modern scientific literacy.

\section{Updates and optimization of teaching contents}

\subsection{Current contents in "new inorganic materials" textbooks}

Through recent teaching and research practice, it has been found that some college students were not able to provide scientific explanations for their research results about inorganic materials in innovation projects, graduation designs, or research projects. The reason for that is because some college students do not fully understand the preparation principle and growth process of new inorganic materials, which in turn affects the understanding and exploration of the principles about inorganic materials. For example, in regard to one-dimensional inorganic materials, the preparation, performance, and application of carbon nanotube and silicon carbide ( $\mathrm{SiC})$ whiskers have been highlighted in "new inorganic materials" textbooks. Other types of one-dimensional materials are often introduced in undergraduate practical projects, such as aluminum carbide $\left(\mathrm{Al}_{4} \mathrm{C}_{3}\right)$, yttrium disilicate $\left(\mathrm{Y}_{2} \mathrm{Si}_{2} \mathrm{O}_{7}\right)$, silicon nitride $\left(\mathrm{Si}_{3} \mathrm{~N}_{4}\right)$, hafnium carbide (HfC), tantalum carbide (TaC) (Figure 1), as well as other high temperature and ultra-high temperature one-dimensional materials, such as silicon nitride / silicon oxide $\left(\mathrm{Si}_{3} \mathrm{~N}_{4} / \mathrm{SiO}\right.$ ), silicon carbide / pyrolytic carbon $(\mathrm{SiC} /$ PyC), titanium dioxide / hafnium carbide $\left(\mathrm{TiO}_{2} / \mathrm{HfO}_{2}\right)$, nickel (II) hydroxide / nickel oxide $\left(\mathrm{Ni}(\mathrm{OH})_{2} /\right.$ $\mathrm{NiO})$ core shell nanowires, silicon dioxide / iron (III) oxide $\left(\mathrm{SiO}_{2} / \mathrm{Fe}_{2} \mathrm{O}_{3}\right)$ equipotaxial one-dimensional material, etc. Moreover, the different morphologies of the same object (such as zero, one-dimensional, and two-dimensional HfC) can be prepared and converted among each other by the same production equipment. Even one-dimensional materials can be in linear, dendritic, axial, and threaded shapes. However, the growth conditions and growth mechanisms of these inorganic materials with different dimensions and different morphologies are not mentioned in current textbooks. There are similar questions about two-dimensional inorganic materials, composites, ceramic materials, and the preparation methods. Therefore, the contents in current textbooks pertaining to inorganic materials cannot meet the needs of modern teaching and research work.

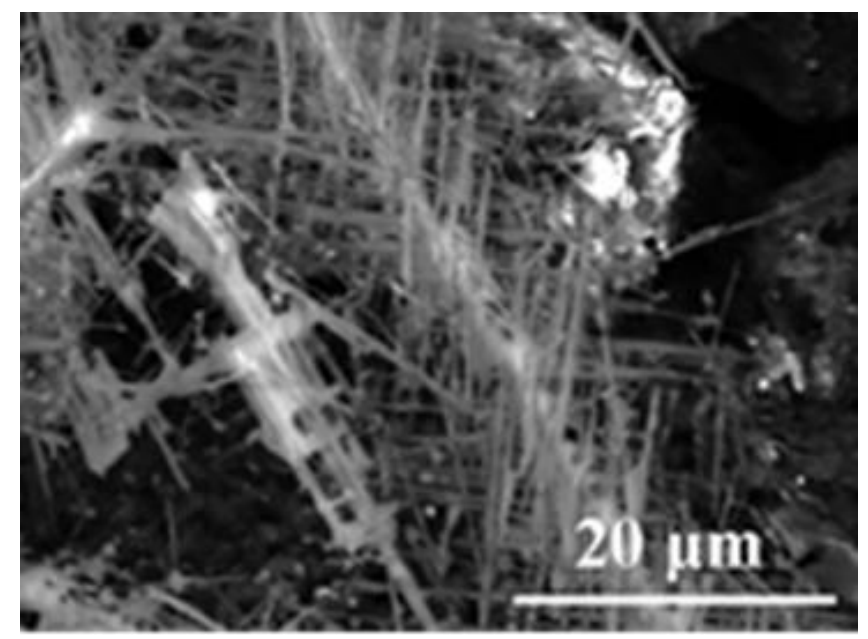

Figure 1. Ultra-high temperature one-dimensional material - tantalum carbide (TaC)

\subsection{Updated teaching contents}

From the perspective of development, textbooks should be relatively stable; however, they should also be constantly enriched with new contents ${ }^{[6]}$. In order to improve students' interest in learning and the learning effects, three measures should be taken into consideration for the reform of the curriculum teaching. Firstly, 
the traditional teaching contents should be refined. The principal knowledge reserves in textbooks and the universal knowledge should be summarized. Contents about relative maturing materials and industrial produced materials should be appropriately deleted and combined. Secondly, the knowledge about new materials and new research theories should be added in textbooks, such as the preparation mechanism and usage of new one-dimensional materials, the functional gradient coatings and thermal protection coatings in the field of aerospace, intelligent and functionalization of inorganic composites, additive manufacturing of inorganic materials, etc. Thirdly, textbooks need to meet the needs of students to carry out innovation projects. Teaching contents that are closely linked with practice should be increased through case teaching in order to consolidate theoretical knowledge and improve students' practical innovation capabilities.

\section{Teaching methods related to the internet}

Appropriate teaching methods are effective ways to impart knowledge to students, which is also the focus of the teaching reform ${ }^{[7]}$.

\subsection{The internet teaching method}

Internet technology does not only effectively expand and supplement the limited textbook knowledge, but also greatly change the traditional teaching method. There are many resources on the internet for teachers and students to use. Students can query certain contents that they are interested in and look for information to solve the problems encountered in books or their innovation projects through the internet. Teachers can use internet platforms to teach and answer questions online. For example, the presupposition of problems before teaching on the internet could help students better grasp key knowledge points. Images, audios, and animations of relevant information on the internet could help students understand more abstract knowledge points. For example, 3D printing technology is a new method of inorganic material preparation, and the latest 3D printing process of material preparation can be obtained through the internet. Teachers can analyze the learning effect as well as the learning data online and further improve their method of teaching. The internet teaching model is shown in Figure 2.

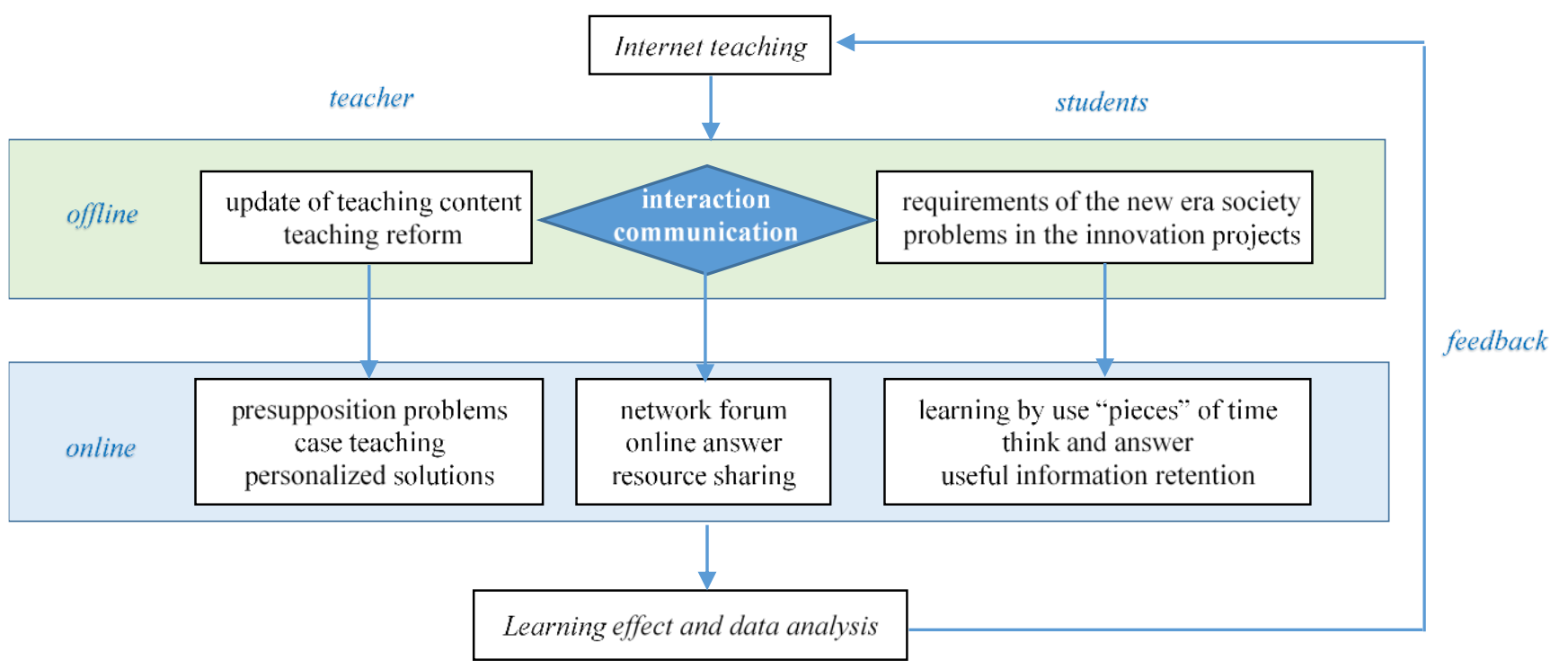

Figure 2. The internet teaching model 


\subsection{Other teaching methods}

The use of blackboard and multimedia in teaching would maximize the teaching effect. The traditional teaching method of using the blackboard is important in classroom teaching. By writing on the blackboard, teaching contents can be organized and condensed. This is conducive to students as it enlightens their thought process and helps them to remember, digest, and consolidate knowledge better. This method of teaching has the characteristics of production and presentation. On the other hand, the use of multimedia in teaching helps students visualize abstract matters and simplify complex problems. With the combination of blackboard and multimedia teaching, multimedia courseware can be used to present the theoretical knowledge and teaching contents that are not easy to present with using the blackboard only; however, the key knowledge points in these contents can be emphasized on the blackboard.

New inorganic materials are widely used in various fields. Case teaching combined with these practical applications can lead to a livelier classroom environment, enhance the interaction between teachers and students, as well as realize the comprehensive improvement of students' quality. Internet related information, the growth process, physical and chemical changes, basic principles, as well as abstract concepts of new inorganic materials can be shown by means of vivid images, audios, and animations, so that students can easily understand what they have learned and strengthen the connection between theory and practice. Teachers can reasonably expand and extent the knowledge points based on their rich scientific research practice and experiences. Students can also discuss the problems encountered in their innovation projects with each other and the teachers to devise better solutions. These events would benefit students by strengthening their understanding of the preparation principle, performance characteristics, and application of materials in actual life as well as scientific research. In addition, the development of teaching and scientific research can be realized at the same time. More than $90 \%$ of students believe that internet teaching is conducive to the understanding of knowledge points and the development of innovation projects.

\section{Build a diversified evaluation system}

Building a diversified evaluation system does not only provide learning orientation, but also direct students' personalized learning characteristics, stimulate students' interests, and establish learning mechanisms to promote learning. The focus of the assessment is not only limited to expertise knowledge, but it also includes learning literacy and learning ability.

The course evaluation is reflected in the final exams, homework, questions during lessons, discussions, presentations, classroom demonstrations, class attendance, cooperation spirit, innovation skills, hands-on ability, and expression skills. The weighted results of the assessment can better explain students' understanding, application, and reflection of professional knowledge as well as their learning literacy and learning ability. Written examinations should not be restricted only to objective questions, such as noun explanation, multiple choice questions, and fill-in-the-blank questions. It is necessary to modify the proportions of subjective questions based on different levels of difficulty. Students should be given the choice to answer subjective questions as well. This would solve the problem of students relying on rote to cope with examinations. In addition, for students who are interested in certain knowledge points and have carried out relevant research pertaining to the subject, this would be an opportunity for them to express their views, thus encouraging their participation and enhancing their sense of achievement. For example, in the course of teaching, it has been found that students are very interested in smart inorganic materials, 3D printing manufacturing technology, sensitive materials, and so on. Other than that, it has also been noted that students developed a deeper understanding and perception of classroom knowledge through the participation of literature review after classes, innovation projects, and other activities. These ideas can be reflected through subjective questions. 


\section{Thoughts on other aspects}

The quality of classroom teaching in colleges and universities depends on teachers, students, and many other factors. Teachers' self-cultivation, knowledge level, and professional skills determine the quality of classroom teaching.

\subsection{Role of teachers}

Teachers need to control the classroom rhythm, guide students to listen and think, as well as improve students' attention and learning interest. At the beginning of each lesson, teachers can use various ways to review the content of the last lesson and to help students transition into the learning stage via discussion or asking questions. Before the end of each lesson, teachers can assign interesting assignments or ask questions related to the key and difficult knowledge points found in the teaching content. Teachers should then guide students to review relevant literatures and arrange a follow-up class to discuss and analyze the questions, in order to stimulate students' desire to explore. Students can also be encouraged to discuss in groups to solve different topics put forward according to the curriculum content. Each group would then share ideas and solutions to the problems with the whole class. This would be very helpful to improve students' team spirit, skills in analyzing and solving problems, and their understanding and mastery of the course knowledge.

\subsection{Role of students}

Modern college students are positive, optimistic, independent, and open-minded with strong learning ability and sense of autonomy. In the process of teaching, it is necessary to break the "superior image" of teachers and create a model of "equality and mutual trust" between teachers and students. Teachers should use their knowledge and experience to explore and discuss with the students, fully respect the students' emotional needs, strive to maintain psychological equality with students, and guide them to venture creatively.

\section{Conclusion}

In order to meet the needs of modern teaching and research work, the content of current textbooks about inorganic materials must be enriched. Students should be aware of relevant emerging research results, such as the preparation mechanism and usage of new one-dimensional materials, the functional gradient coatings and thermal protection coatings in the field of aerospace, intelligent and functionalization of inorganic composites, as well as additive manufacturing of inorganic materials. Internet teaching is conducive to both teachers and students in teaching and learning, respectively. The teaching reform and teaching methods related to the internet involve scientific, wide-ranging, and far-reaching system engineering. Only by constantly summing up teaching experiences, adhering to the student-centered approach, daring to explore and practice, as well as constantly improving and supplementing, then the teaching quality of new inorganic materials can be improved.

\section{Funding}

This study was supported by the National Natural Science Foundations of China (Grant Number: 51772247).

\section{Disclosure statement}

The authors declare that there is no conflict of interest. 


\section{Author contributions}

Xiaohong Shi conceived the idea of the study and wrote the paper. Kezhi Li provided guidance and suggestions for the research.

\section{References}

[1] Hedan B, Robert FS, 2021, The New Material Science of Robots. Current Opinion in Solid State and Materials Science, 25(2): 1-6.

[2] Rahul S, Pramod KS, Bhattacharya B, et al., 2019, Review of Current Progress in Inorganic Holetransport Materials for Perovskitesolar Cell. Applied Materials Today, 14: 175-200.

[3] Xie S, Liu Y, Wu Z, et al., 2015, Application of Inorganic Layered Materials in Electrochemical Sensors. Chinese Journal of Analytical Chemistry, 43(11): 1648-1655.

[4] Nagaraj PS, Savio D, Kakarla RR, 2019, Nanostructured Organic and Inorganic Materials for Li-ion Batteries: A Review. Materials Science in Semiconductor Processing, 104: 104684.

[5] Wu P, 2017, Development and Trend of the Technology and Industry for New Inorganic Nonmetallic Materials. Technology Outlook, 29: 96.

[6] Zhang M, 2004, The Compiling Principles of Improving the Quality of College Teaching Materials. Journal of Zhejiang University (Humanities and Social Sciences Edition), 34: 44.

[7] $\mathrm{Hu}$ H, Wu Y, E Y, et al., 2019, The Dual Balance between Teaching and Learning in the New Situation of Teaching Reform - The Reform of Classroom Teaching and the Development of Students, Education Modernization, 6: 33-35. 